\title{
Attractiveness, values and evaluations of non-celebrities in print ads: An exploratory study
}

\author{
S.M. Burgess* \\ Graduate School of Business, University of Cape Town, Breakwater Campus, \\ Private Bag, Rondebosch 7701, Republic of South Africa \\ sburgess@gsb.uct.ac.za \\ R.D. Blackwell \\ Fisher College of Business, The Ohio State University, United States of America
}

Received March 2001

\begin{abstract}
Noncelebrity endorsers are receiving renewed interest because of rising celebrity endorsement fees and perceptions of risk associated with celebrity endorsements. USA and South African university students rated the attractiveness of a noncelebrity endorser appearing in an alcoholic beverage ad, their desire to associate with her and approve of her behaviour, and their value priorities. The results suggest that value priorities influence noncelebrity endorser evaluations directly and indirectly. More specifically, perceived attractiveness partially mediated the effect of value priorities, confirming Kelman's (1961) contentions. Attractiveness appears to be more useful when consumers assess their desire to associate with a noncelebrity endorser while values appear to be more useful in evaluating a noncelebrity endorser's behaviour.
\end{abstract}

*To whom all correspondence should be addressed.

\section{Introduction}

People generally seem to believe that 'what is beautiful is good' and advertisers seem willing to bet they are right - to the tune of hundreds of millions annually. It appears to be a safe bet, whether consumers judge spokespeople and models in ads ('endorsers') to be attractive because of their physical appearance or their ideological similarity (e.g., similarity in values and beliefs (Kelman, 1961)). Few findings in psychological research have been more persistent than those suggesting people find attractive people to be more persuasive, competent, credible, intelligent, mentally healthy, popular, socially-skilled, and sexually warm, even if they may not be (Eagly, Ashmore \& Longo, 1991; Feingold, 1992; Jackson, Hunter \& Hodge, 1995). Moreover, traits related to physical attractiveness are among the most powerful influences when people form impressions of others (Tanke, 1982).

The bulk of scholarly interest in endorser attractiveness has focused on celebrities (Wilson \& Sherrell, 1993). Celebrity endorsement is a prevailing form of advertising and the number and value of celebrity endorsement contracts has been increasing steadily (Agrawal \& Kamakura, 1995). Nevertheless, advertisers are reconsidering the use of celebrity endorsers and not just because of rising endorsement fees. Paradoxically, something most celebrities would consider their greatest asset — the pre-existing meaning consumers associate with them - may be their greatest liability in a globalised, hypermediated communication environment.
Hounded by the paparazzi and constant public scrutiny, the risk of negative publicity stalks celebrities. Such intense scrutiny has tarnished even 'squeaky-clean' celebrities such as O.J. Simpson, Hugh Grant, and South African cricketer Hansie Cronje (c.f., Till \& Shimp, 1998). Negative publicity can threaten the basis of celebrities' perceived attractiveness (e.g., similarity in moral values) and the 'match-up' between their image and a target market or product category (see, Kahle \& Homer, 1985; Kamins, 1990). Advertisers appear to be going so far as to use deceased celebrity endorsers such as Humphrey Bogart and John Wayne in order to reduce the risk of such negative publicity; however, celebrity endorsements entail additional risks that advertisers must consider. For instance, multiple product endorsements introduce risks. A celebrity's effectiveness as an endorser depends on her ability to impart appropriate cultural meaning to consumers in an increasingly globalised advertising environment. Probably only a handful of celebrities present a reasonably consistent set of meaning associations outside their home countries....and they are highly sought after. Celebrities that endorse multiple products are less credible and likeable and the ads they appear in garner lower overall ratings (Tripp, Jensen \& Carlson, 1994). Just as meaning transfers from celebrity to product to consumer, so too it transfers from consumer to product to celebrity. Companies that use multiple product celebrity endorsers may find undesirable associations from other products the celebrity endorses (e.g., safety or quality problems) are reflected onto a company's own products through the endorser.

Advertisers who use noncelebrity endorsers avoid many of 
the risks of celebrity endorsement but there is some question about how effectively noncelebrities communicate meaning. Intuitively, advertisers can endow the physical appearance of even the most ordinary people with cues that communicate desirable meaning associations (e.g., a stethoscope and doctor's coat, heavy-metal guitar and hairstyle). However, there is little evidence in the scholarly research linking noncelebrity endorser appearance to meaning.

One way to advance our understanding is to study the relations of consumer value priorities and evaluations of noncelebrity endorsers. People experience meaning in life when they attain important values (Frankl, 1959). Value priorities direct consumer attention to the utilitarian and hedonic meaning in ads and influence product choices directly and indirectly via means-end associations (Allen \& $\mathrm{Ng}, 1998$ ). Although the influence of values on ad evaluations has been anticipated for decades (e.g., Engel, Kollat \& Blackwell, 1968; Kelman, 1961; Postman \& Scheider, 1951), a reliable and systematic basis for comprehensively testing value relations to external variables was not available. This deficiency was remedied recently when Schwartz proposed a theory on the universal content and structure of human values, designed instruments to test it, and reported consistently supportive results in tests of more than 100,000 respondents in over 60 countries and on every inhabited continent (Schwartz, 1992; Schwartz, 1994; Schwartz, Lehmann \& Roccas, 1999). Despite impressive empirical support, the theory has received little attention in marketing (for exceptions, see Burgess \& Blackwell, 1994; Burgess \& Steenkamp, 1999; Grunert-Beckmann \& Askegaard, 1997; Steenkamp, Ter Hofstede \& Wedel, 1999). This is regrettable because the theory provides a powerful platform for testing hypotheses relating values to other variables. The current research uses the theory to test the relations of (a) perceived noncelebrity endorser attractiveness (viz., physical attractiveness and similarity), (b) consumer value priorities, and (c) evaluations of noncelebrity endorsers.

\section{Literature review}

In this section, we briefly review the literature concerning endorser attractiveness, consumer values, and consumer evaluations of others and formalise a set of hypotheses. Physical attractiveness and similarity of the endorser rarely have been studied together (Wilson \& Sherrell, 1993). We begin by exploring these two major elements of endorser attractiveness.

\section{Endorser physical attractiveness}

The persuasive influence of physically attractive/ unattractive endorsers has been explained from many theoretical perspectives (reviewed by Eagly et al., 1991; Feingold, 1992; Jackson et al., 1995). For instance, affective responses to physical attractiveness are thought to influence evaluations directly and stimulate further cognitive elaboration (Van Raaij, 1989). As an unconditioned stimulus, physical attractiveness may pair with the conditioned stimulus of the person, resulting in a biased response to the person and associated products in an ad. Physical attractiveness may promote systematic processing when beauty or health is an evaluative outcome (Chaiken,
1980). As a diffuse status characteristic, physical attractiveness may foster expectation states regarding credibility by generalising to other characteristics of the person and the environment. It may act as a peripheral cue in conditions of low involvement but as a persuasive message argument in high involvement (Petty \& Cacioppo, 1986). Physical attractiveness may instigate impressionrelevant involvement by drawing attention to the instrumental meaning of beliefs (including values) and actions in relation to the impressions of others (Chaiken, 1980). Thus, there is ample evidence suggesting that physical attractiveness relates to values and also to consumer evaluations of noncelebrity endorsers.

\section{Endorser similarity}

Evaluations of endorsers also may be biased by perceptions of physical or ideological similarity/disimilarity (Hart \& Diehl, 1994; Kelman, 1961; Woodside \& Davenport, 1974). Similarity is thought to generate emotional responses that affect ad cognitions directly and through subsequent cognitive elaboration. It may generalise to an expectation of mutual need gratification based on reciprocal liking (Berscheid \& Reis, 1998). From an elaboration likelihood perspective, similarity may act as a persuasive message argument by indicating that a product is especially for people that share a salient characteristic. Even when the basis of similarity is not salient, similarity may create a feeling of warmth that acts as a peripheral cue (Aaker \& Stayman, 1989). Similarity may act as an unconditioned stimulus, evoking a positive affective response by validating one's own beliefs (Byrne, London \& Reeves, 1968). Johnson \& Eagly (1990) contend that similarity affects central and peripheral route processing by triggering value-relevant involvement. These propositions suggest that similarity is related to values and to evaluations of noncelebrities.

\section{Consumer values}

Values influence most aspects of consumer behaviour, including ad evaluations (Burgess, 1992). Values are transsituational goals that refer to desirable end-states and modes of conduct, vary in importance, and serve as principles that guide behaviour and evaluations (Schwartz, 1992). People evaluate the content of ads for congruency with values, attitudes, and other beliefs in a process that links ad elements to stored symbolic representations of people, brands, events, and interaction episodes (Rokeach, 1973). This process is intrinsic to constructing identity and includes complex affective and cognitive evaluations (Baumgartner, Sujan \& Bettman, 1992). Recent research on means-end theory and goal-directed behaviour has improved our understanding of how people link the content of print ads to their value priorities. Substantial progress can be traced to the development and refinement of the laddering methodology by Gutman, Reynolds, and other means-end researchers (e.g., see Olson, 1995). Laddering research has suggested that situational cues and internal stimuli prompt consumers to associate executional elements in ads, including visual images, to ever more deeply held consequential associations that ultimately lead to core values (i.e., means-end chains of associations, see Bagozzi \& Dabholkar, 1994; Grunert-Beckmann \& Askegaard, 1997; 
Reynolds, Gengler \& Howard, 1995; Ter Hofstede, Steenkamp \& Wedel, 1999). Although the content, complexity, and integration of these 'attributeconsequence-value' chains has been related to differences in specific knowledge and knowledge-based inferences, the evidence suggests that people share substantially similar means-end associations (Bagozzi, Baumgartner \& Pieters, 1998; Bagozzi \& Dabholkar, 2000; Pieters, Baumgartner \& Allen, 1995). Thus, means-end chain theory provides a framework for suggesting that endorser characteristics evident in a print ad, such as attractiveness, ultimately trigger relatively predictable associations to value priorities.

\section{Schwartz' theory of value content and structure}

According to Schwartz (Schwartz, 1992; Schwartz, 1994), values form in response to three universal requirements of human existence to which all individuals and societies must respond: the needs of individuals as biological organisms, the requisites of coordinated social action, and the survival and welfare needs of groups. These requirements are the basis for the motivational content and structure of values proposed by the theory. The hypothesised interrelations of values imply a circular structure (i.e., a circumplex, see Figure 1) in which ten motivational value types conveniently segment a continuum of related motivations. Values in closest proximity on the circumplex are most compatible and most positively correlated. For example, stimulation and hedonism both entail a desire for affectively pleasant arousal. Values in opposition are most conflicted and most negatively correlated. The pursuit of independence-oriented values such as stimulation or hedonism may conflict with the desire to maintain harmony with others implied by the pursuit of conformity and tradition values. Similarly, relations to external variables will be most positive with values located in proximity along the circumplex and most negative with values located in opposition. Table 1 outlines the value types and identifies values typically included in the content of each.

Table 1: Value types in Schwartz's value theory

\begin{tabular}{|c|c|c|}
\hline Value type & Definition & Exemplary values \\
\hline Power & $\begin{array}{l}\text { Social status and prestige, control or dominance over people } \\
\text { and resources. }\end{array}$ & Social power, authority, wealth \\
\hline Achievement & $\begin{array}{l}\text { Personal success through demonstrating competence } \\
\text { according to social standards. }\end{array}$ & Successful, capable, ambitious \\
\hline Hedonism & Pleasure and sensuous gratification for oneself. & Pleasure, enjoying life \\
\hline Stimulation & Excitement, novelty and challenge in life. & Daring, varied life, an exciting life \\
\hline Self-direction & $\begin{array}{l}\text { Independent thought and action-choosing, creating, } \\
\text { exploring. }\end{array}$ & Creativity, curious, freedom \\
\hline Universalism & $\begin{array}{l}\text { Understanding, appreciation, tolerance, and protection for } \\
\text { the welfare of all people and nature. }\end{array}$ & $\begin{array}{l}\text { Broadminded, social justice, equality, } \\
\text { protecting the environment }\end{array}$ \\
\hline Benevolence & $\begin{array}{l}\text { Preservation and enhancement of the welfare of people with } \\
\text { whom one is in frequent personal contact. }\end{array}$ & Helpful, honest, forgiving \\
\hline Tradition & $\begin{array}{l}\text { Respect, commitment, and acceptance of the customs and } \\
\text { ideas that culture or religion provide. }\end{array}$ & $\begin{array}{l}\text { Humble, devout, accepting my portion in } \\
\text { life }\end{array}$ \\
\hline Conformity & $\begin{array}{l}\text { Restraints of actions, inclinations, and impulses likely to } \\
\text { upset or harm others and violate social expectations or } \\
\text { norms. }\end{array}$ & $\begin{array}{l}\text { Politeness, obedient, honoring one's } \\
\text { parents or elders }\end{array}$ \\
\hline Security & $\begin{array}{l}\text { Safety, harmony, and stability of society, of relationships, and } \\
\text { of self. }\end{array}$ & Social order, clean \\
\hline
\end{tabular}

Source: Excerpted from Schwartz (1992). 


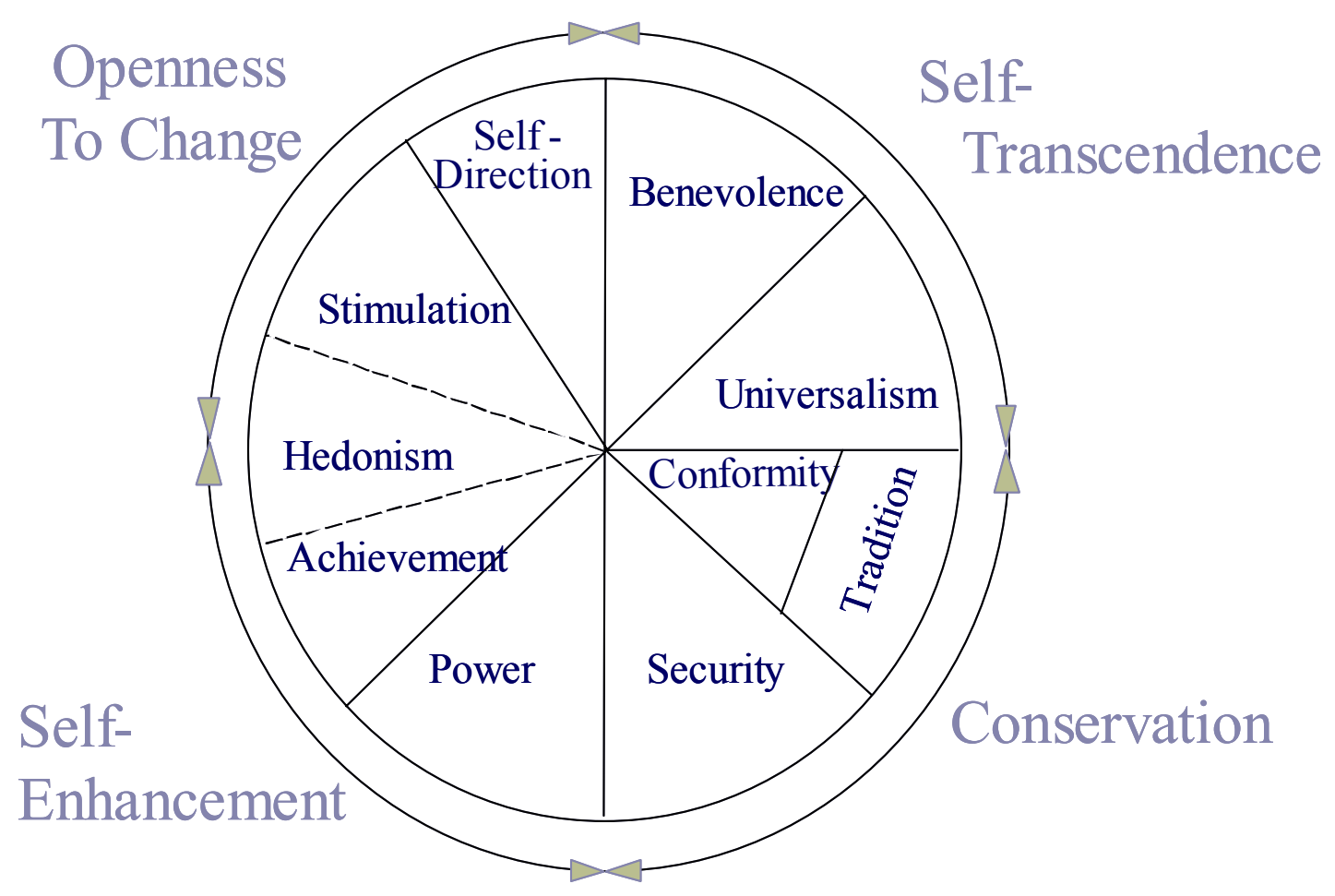

Figure 1: Motivational value types and higher order value domains

Note: Adapted from Schwartz (1992).

The theory also proposes two major value domains (shown on the periphery of Figure 1, see Schwartz, 1994), which reflect two higher-level conflicts that have emerged in more than $95 \%$ of the studies conducted by Schwartz and his associates. One possibly bipolar dimension opposes openness to change to conservation. This places independent thought and action and favouring change in conflict with submissive self-restriction and preservation of traditions, customs, and stability. On the other possibly bipolar dimension, self-enhancement opposes self-transcendence. This places concern for the equality and welfare of others and protection of the environment in opposition to the pursuit of personal success and ascendancy over others. Feather (1995) posits that the mean of a person's scores on the opposing value domains will produce two useful indices of basic value priorities: resultant openness to change and resultant self-enhancement. We use these indices to operationalise values in the current research.

\section{Noncelebrity evaluations}

Preceding sections suggest that we may confidently predict bivariate relations between (1) endorser attractiveness, (2) consumer value priorities, and (3) consumer evaluations of endorsers. In this section, we consider the interrelatedness of these constructs, which are elements of identity in Kelman's (1961) seminal theory on processes of opinion change. Although Kelman's theory has received empirical support and enjoys such respect that it has been called "the third classical theory of attitude function" by influential social psychologists (e.g., Eagly \& Chaiken, 1993:498), it has not received much empirical attention in the marketing literature.
Kelman proposed two processes in which an encounter with an attractive endorser could instigate biased evaluations related to value priorities. During identification, the encounter activates self-defining role relations or reciprocalrole relations as well as concern for the social anchorage of one's behaviour. The consumer responds with a biased evaluation of the endorser in order to establish or maintain a self-perceived relation to the endorser, even if the encounter takes place outside the physical presence of the endorser (e.g., in response to an ad). Identification suggests a process in which attractiveness mediates the influence of value associations on consumer evaluations of endorsers but only within the context of the roles and statuses that are activated by the encounter. Kelman hypothesised that means-end chain associations induced during identification would 'remain separate from the rest of the person's values - to have little interplay with them' (Kelman, 1961:70-71). However, he also proposed a process in which values relate directly to source evaluations. Internalisation results when an encounter with an endorser instigates concern for the value congruence of one's behaviour with that of the endorser. Kelman proposed that credible endorsers could change a consumer's perceptions of the conditions necessary for value maximisation. In turn, this could prompt elaboration and appraisals that induce the reorganisation of means-end relations (including the most centrally-held value priorities and perceptions of identity) or, alternatively, confirm the status quo. Kelman theorised that identification and internalisation need not be mutually-exclusive processes but rather conceptualised them as idealised points on a continuum of processes of opinion change. Thus, Kelman's theory suggests direct and indirect relations between consumer value priorities and endorser evaluations will 
emerge as consumers reference their identity as members of groups and as individuals.

Recent findings on social identity and social categorisation are consistent with Kelman's contentions. Values, personality traits, and salient characteristics associated with roles and status in society, such as attractiveness, are the key components of identity (Camilleri \& Malewska-Peyre, 1997; Higgins, 1996). People are members of many groups and an encounter with an endorser may activate many relevant social identities to help guide the behavioural choices a person makes as a social being. Shared personal values and traits become stereotypical group attributes — 'we're like this and they're like that' - which impact on evaluations and foster shared, almost altruistic, social identifications because group needs are perceived as one's own (Turner, 1984; Zavalloni, 1975). Endorsers, like others, provide visual and behavioural cues about their identity and with whom they wish to associate in a given situation (Camilleri \& Malewska-Peyre, 1997; DePaulo, 1992). Any salient and situationally meaningful ingroup-outgroup distinction that is observed (even those based on differences in subtype) may be sufficient to activate differential affective, cognitive, and behavioural responses to an endorser (see Biernat, Vescio, Theno \& Crandall, 1996; Brewer \& Brown, 1998). As a result, endorsers from the salient in-group are evaluated more favourably while others are evaluated less favourably (e.g., Jackson, Sullivan \& Hodge, 1996; Jetten, Spears \& Manstead, 1996). Consumers also act as individuals and may find that activated social identities are in conflict. Alternatively, one may have trouble choosing which social identity is most salient, if any. In such cases, whether one actively selects the most salient identity or allows multiple identities to influence an evaluation, a consumer may consult personal value priorities in order to guide evaluations.

In the current research, we measure two ultimate dependent variables. First, we measure a primarily social evaluation: the desire to associate with the endorser. We reason that people scan endorsers for visual and behavioural information to evaluate salient group membership and selfdefining role or reciprocal-role relations, although the relations need not take place in reality and the parties may never meet. Nevertheless, it is clear that the nature of a selfdefining relationship implies a requirement to desire to associate with an endorser, even if in fantasy. Second, we measure a primarily personal evaluation: the respondent's approval of the endorser's behaviour. We reason that an encounter with an endorser activates many social identities, some of which may be in conflict. This causes the consumer to ultimately make evaluations that are guided by personal value priorities. Thus, we reason that consumer evaluations of endorsers will ask, at least in part, 'Would people like me associate with the endorser in this ad?' and 'Do I approve of the endorser's behaviour depicted in this ad?' We test these two evaluations of endorsers by asking respondents if they would (1) associate with the endorser in the ad and (2) approve of the behaviour depicted in the ad ('noncelebrity endorser evaluations' in our hypotheses below).

\section{Hypotheses}

We may now proceed to formalise some predictions about the nature of relations between noncelebrity endorser attractiveness, consumer value priorities, and noncelebrity endorser evaluations. The first two hypotheses concern the effect of attractiveness on noncelebrity endorser evaluations. We expect a person's evaluations of the noncelebrity endorser (viz., the desire to associate with her and approve of her behaviour) to increase (decrease) in relation to perceptions of her physical attractiveness (unattractiveness). We expect evaluations of the noncelebrity endorser to vary likewise in relation to her perceived similarity (dissimilarity).

$\mathrm{H}_{1 \mathrm{a}}$ : Consumers will be more positive (negative) about associating with a physically attractive (unattractive) noncelebrity endorser and will evaluate her behaviour more favourably (negatively).

$\mathrm{H}_{1 \mathrm{~b}}$ : Consumers will be more positive (negative) about associating with a similar (unattractive) noncelebrity endorser and will evaluate her behaviour more favourably (negatively).

The next two hypotheses concern the effect of values on the perceived attractiveness of noncelebrity endorsers. We use Schwartz' value domains to operationalise value priorities. Following Schwartz (1992), value type scores are calculated by averaging the scores of the scale items comprising each value type. Value domain scores are computed by averaging the value type scores comprising each value domain. Following Feather (1995), we compute resultant openness to change and resultant self-enhancement. We expect that the perceived attractiveness of noncelebrity endorsers will be related to a respondent's value priorities (i.e., that people with similar values will be perceived to be more attractive). We test a noncelebrity endorser that has been chosen because her appearance, behaviour, and context suggest that she endorses hedonism, stimulation, and self-direction (viz., openness to change values). Thus, we expect that perceptions of a noncelebrity endorser's physical attractiveness (unattractiveness) and similarity (dissimilarity) will vary according to the 'match-up' of consumer value priorities and the perceived value priorities of the noncelebrity endorser. If this is true, then people who place higher priority on openness to change values will perceive the noncelebrity endorser to be more physically attractive and similar (and vice-versa). However, as the two higher order bipolar dimensions are theorized to be nearly orthogonal and the ad has been chosen to imply nothing about self-enhancement or self-transcendence, we hypothesize that resultant self-enhancement will not be related to noncelebrity endorser evaluations.

$\mathrm{H}_{2 \mathrm{a}}$ : The importance of resultant openness to change will be related to the perceived physical attractiveness of a noncelebrity endorser when the noncelebrity endorser is perceived to endorse openness to change values. Resultant selfenhancement will not be related to perceived physical attractiveness in this case. 
$\mathrm{H}_{2 \mathrm{~b}}$ : The perceived similarity of a noncelebrity endorser will be related positively to resultant openness to change when the noncelebrity endorser is perceived to endorse openness to change values. Resultant self-enhancement will not be related to perceived similarity in this case.

As a result of the selection criteria for the ad, we expect the endorser and her behaviour will imply her active support for resultant openness to change but imply nothing about resultant self-enhancement. Moreover, we expect that a respondent's desire to associate with the endorser and approve of her behaviour will vary according to the 'matchup' of the respondent's value priorities and these apparent value priorities of the noncelebrity endorser. Therefore, we expect that the importance a person places on resultant openness to change will affect her desire to associate with a noncelebrity endorser and approve of her behaviour. However, for the same reasons noted above, we hypothesize that resultant self-enhancement will not be related to noncelebrity endorser evaluations.

$\mathrm{H}_{3 \mathrm{a}}$ : The desire to associate with a noncelebrity endorser who is perceived to endorse openness to change values will vary according to the importance a consumer places on resultant openness to change but not according to the importance placed on resultant self-enhancement.

$\mathrm{H}_{3 \mathrm{~b}}$ : Approval of a noncelebrity endorser's behaviour who is perceived to endorse openness to change values will vary according to the importance a consumer places on resultant openness to change but not according to the importance placed on resultant self-enhancement.

Finally, we expect values to have a direct effect on noncelebrity endorser evaluations as well as an indirect effect that is mediated by attractiveness. Thus, we expect that attractiveness will partially mediate the effect of a person's value priorities on their desire to associate with a noncelebrity endorser and approve of her behaviour.

$\mathrm{H}_{4 \mathrm{a}}$ : The perceived physical attractiveness of a noncelebrity endorser partially mediates the effect of resultant openness to change on the desire to associate with a noncelebrity endorser who is perceived to endorse openness to change values.

$\mathrm{H}_{4 \mathrm{~b}}$ : The perceived similarity of a noncelebrity endorser partially mediates the effect of resultant openness to change on the approval of a noncelebrity endorser's behaviour when the noncelebrity endorser is perceived to endorse openness to change values.

\section{Covariates}

In order to control for spurious effects and to obtain a more precise test of our hypotheses, we added appropriate covariates in the regression analyses (c f., McCarty \& Shrum, 1993). Gender is an antecedent of attractiveness, similarity, and value priorities and was included in all tests
(Byrne et al., 1968; Chaiken, 1979). Two additional covariates were included in analyses in which values appeared as an independent variable. Optimum stimulation level is a personality trait that is related to stimulation, hedonism, and self-direction values (Burgess \& Steenkamp, 1999). Following Schwartz (1992), the mean rating assigned to the 29 PQ scale items by each respondent was included to control for differences in scale use. Although other international findings suggest ethnicity may result in biased judgments of physical attractiveness (Cunningham, Roberts, Barbee, Druen \& Wu, 1995), it did not in the current research and we omitted it from the final analysis for the sake of brevity in reporting our results. Standard collinearity and residual diagnostics indicated that the data were amenable to linear regression.

\section{METHOD}

\section{Sample and instrument}

The sample consisted of 122 South African and 264 USA undergraduate marketing students (hereafter results in the text are reported in that order separated by a '/'). The instrument was a self-completion survey and the alcoholic beverage ad was projected on a screen at the front of the class. Using a five-point Likert scale, respondents reported their perceptions concerning (1) how similar the central character was to them and (2) their friends, (3) her physical attractiveness, (4) whether they would associate with her, and (5) whether they approved of her behaviour. Items 1 and 2 were summated to create an index of similarity (Cronbach's $\alpha=.82$ / .71). Respondents also completed the Portraits Questionnaire, a new shortened values scale developed by Schwartz (PQ, Schwartz, Melech, Burgess \& Harris, 2001; Schwartz et al., 1999), Steenkamp and Baumgartner's Shortened Change Seeker Index (CSI), (Steenkamp \& Baumgartner, 1995), and a short battery of demographic questions. Respondents were instructed to observe the ad as they might normally when reading a magazine and to provide answers that reflected their own opinions. Class members collected completed questionnaires in boxes and a respondent's identity could not be inferred from the completed survey. Three completed questionnaires from the USA sample and two from South Africa were excluded because respondents assigned the same rating to more than 21 values or the same ratings to more than 14 values consecutively, suggesting carelessness (see Schwartz, 1992). Three other USA questionnaires were unusable.

\section{Ad stimulus}

Alcoholic beverage ads for youth markets typically select central characters for their physical attractiveness and similarity to the target audience and depict them engaging in stimulating activities or enjoying stimulating environments (Aitken, 1989a; Aitken, 1989b; Aitken, Eadie, Leathar, McNeill \& Scott, 1988). Verbal and nonverbal social influence cues often are chosen to enhance persuasion (Biddle, Bank \& Marlin, 1980; Pechmann \& Shih, 1999; Schooler, Basil \& Altman, 1996). The ad stimulus was chosen in a two-step process. First, all beverage ads depicting noncelebrities and appearing in current quarter issues of twenty major South African magazines targeted at 
the respondent age group were analysed for content by a small group of South African student administrators and 35 unique ads were selected for further study. Then, two focus groups, consisting of students at the University of the Witwatersrand, were tasked with selecting the ad with noncelebrity and background characteristics that most endorsed hedonism, stimulation, and self-direction (viz., openness to change values) (Hirschman, 1984; McAlister \& Pessemier, 1982; Raju, 1980; Steenkamp \& Baumgartner, 1992; Zuckerman, 1994). Both focus groups selected a new ad for Nordic Ice vodka (see Figure 2).

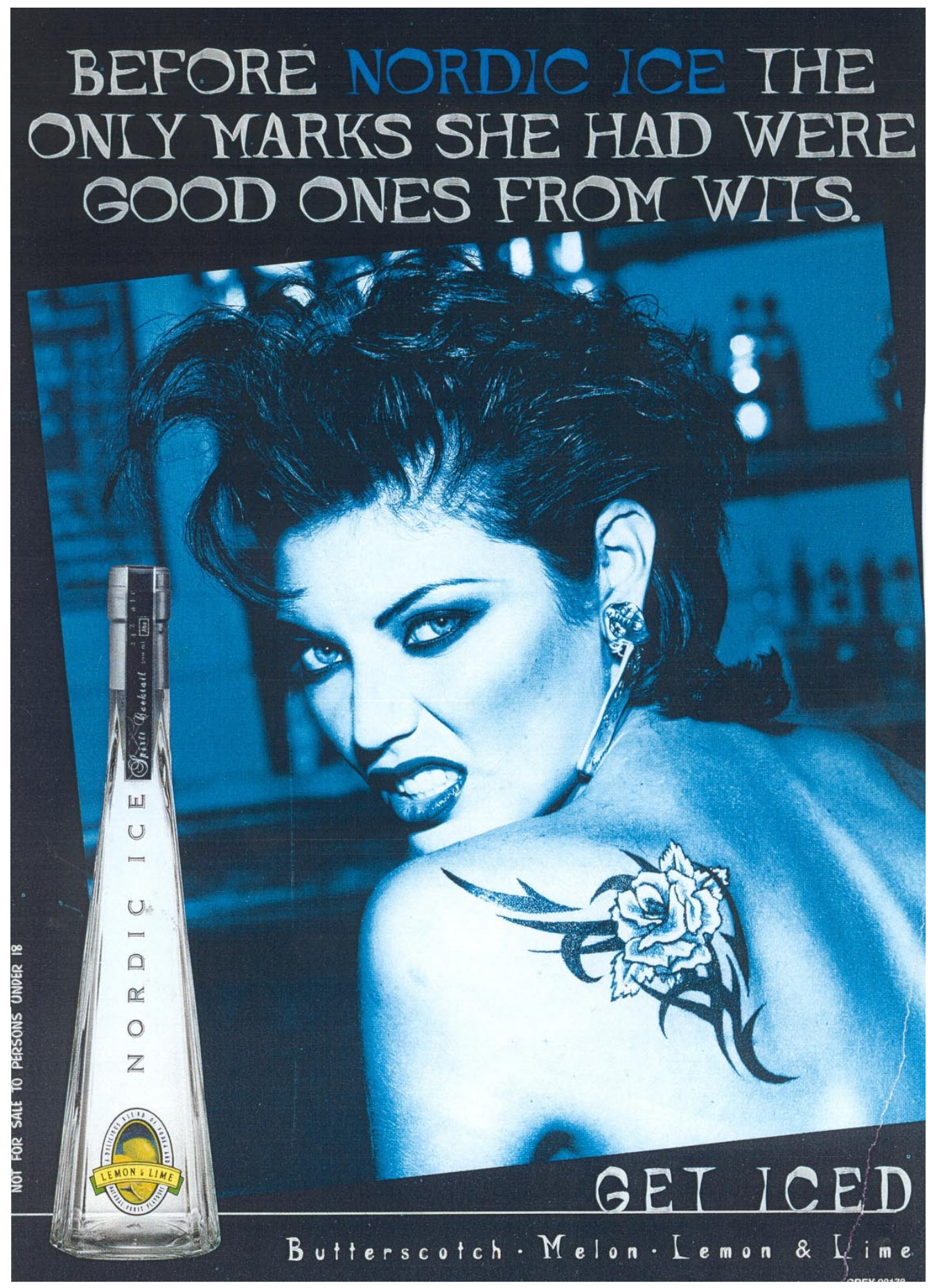

Figure 2: Nordic ice advertisement 


\section{Meaning equivalence}

The product and the ad were new in South Africa and the brand was not available in the USA. The headline used a clever turn of phrase that referred to a well-known South African university (the University of the Witwatersrand, 'Wits') but which had no meaning in the USA (see Figure 2). 'Marks' are 'grades' in the USA and the double meaning was lost concerning the endorser's shoulder tattoo (i.e., 'marks') and her 'good marks' at university. We carefully considered the need to maintain meaning equivalence across cultures, reviewed the themes South African respondents reported in the first phase, and then conducted a focus group with some South African study participants to better understand their perceptions of the phrase. We then conducted a focus group to discuss the meaning of potential headlines with students at the American university where the research was to be conducted. As a result, the USA headline was changed to: 'Before Nordic Ice, she was Mommy's good little girl at Ohio State.'

Respondents in both samples indicated the perceived themes in the ad by choosing from a list of 24 themes culled from previous reviews concerning thematic perceptions of alcoholic beverage ads (Breed \& DeFoe, 1979; Finn \& Strickland, 1982; Strickland, Finn \& Lambert, 1982). The thematic perceptions of both samples were almost identical and were consistent with previous findings of themes that interest people with high stimulation preferences. As expected, 'rebellion' $(90 \% / 86 \%)$ and 'sexuality or sexual connotations' $(89 \% / 80 \%)$ were the most commonly noted themes. About $80 \%$ of both samples also perceived 'adventure or risk' or 'intoxication or heavy drinking' in the ad.

\section{Scale reliability and validity}

We then confirmed the reliability and validity of the values and optimum stimulation level scales. Following the configural verification approach advocated by Schwartz (1992), we used Smallest Space Analysis (SSA) (Guttman, 1968) to test for the hypothesized structure of PQ. The SSA produced Schwartz's hypothesized content and structure except that benevolence and universalism reversed position and stimulation emerged as a distinct region located on the periphery of self-direction for South Africans. For the USA, three value types emerged as distinct regions somewhat different than expected: conformity was located between tradition and security, universalism on the periphery of benevolence, and power values on the periphery of achievement. Schwartz (1992) reports that hedonism may emerge as an openness to change or self-enhancement value. It emerged as an openness to change value in the current research. Minor variations such as these are consistent with the theory and the probability of achieving a random result as close as these results to the hypothesized structure is less than .01 . The results are exceptionally good given the small size of the samples (Schwartz, 1992).

Confirmatory factor analysis was performed to test a onefactor model for the CSI scale. The analyses used the maximum likelihood method of parameter estimation and all analyses were performed on the variance-covariance matrix.
Model fit indices suggest a very good fit to a onedimensional model: South Africa, $X^{2}(14)=17.87, p>.20$, root mean square error approximation (RMSEA) $=.048$, comparative fit index (CFI) $=.998$, Tucker-Lewis index $(\mathrm{TLI})=.996$ and USA, $\mathrm{X}^{2}(14)=38.16, \mathrm{p}<.0001$, RMSEA $=$ $.079, \mathrm{CFI}=.961$, and $\mathrm{TLI}=.942$.

\section{Results}

In this section, we test our hypotheses using linear regression and report the results. We note that the mediation hypothesis proposed in $\mathrm{H}_{4}$ requires support for $\mathrm{H}_{1}, \mathrm{H}_{2}$, and $\mathrm{H}_{3}$ (otherwise, the relationships required for mediation do not exist). If $\mathrm{H}_{1}, \mathrm{H}_{2}$, and $\mathrm{H}_{3}$ are supported, then $\mathrm{H}_{4}$ may be tested using the procedure of Baron and Kenny (1986).

\section{Attractiveness and noncelebrity endorser evaluations}

The results support $\mathrm{H}_{1 \mathrm{a}}$ and $\mathrm{H}_{1 \mathrm{~b}}$ and the standardized regression coefficients are significant. The effect sizes for the noncelebrity characteristics of attractiveness and similarity compare very favourably with previous research on source effects $\left(.074 \leq \eta^{2} \leq .241\right)$ (c.f., Wilson \& Sherrell, 1993). The effect size is comparably larger when association is regressed on physical attractiveness and similarity than when approval is regressed on the same variables (up to more than three times larger). South African females were less likely to approve of the behaviour depicted in the ad than males, but gender was not related to noncelebrity endorser evaluations otherwise.

\section{Value priorities and noncelebrity characteristics}

The results support $\mathrm{H}_{2 \mathrm{a}}$ and $\mathrm{H}_{2 \mathrm{~b}}$. $\mathrm{R}^{2}$ is significant for both models suggesting an acceptable fit. Resultant openness to change is positively associated with both source perceptions, while resultant self-enhancement is associated with neither, producing an effect size near zero. The OSL covariate is not associated with physical attractiveness or similarity for South Africans, but it is for respondents from the USA. Female students rate the noncelebrity endorser's attractiveness lower than males in both countries. In like fashion, USA females find themselves to be less similar to the noncelebrity endorser than USA males.

\section{Noncelebrity endorser evaluations and value priorities}

The results also support $\mathrm{H}_{3 \mathrm{a}}$ and $\mathrm{H}_{3 \mathrm{~b}}$ : resultant openness to change affects both noncelebrity endorser evaluations while resultant self-enhancement affects neither. The coefficients of determination are significant for both models. The effect size is noticeably larger when approval is regressed on value priorities; however, effect sizes for both regressions compare favourably with previous source effect studies. The effect of OSL is not significant. Females were less likely to approve of the behaviour depicted in the ad and less willing to associate with the noncelebrity endorser. 
Table 2: Regression summaries

\begin{tabular}{|c|c|c|c|c|c|c|c|c|c|}
\hline \multirow[t]{4}{*}{ Independent Variables } & & \multicolumn{8}{|c|}{ Dependent variables } \\
\hline & & \multicolumn{4}{|c|}{ Hypotheses $1_{\mathrm{a}}$ and $1_{\mathrm{b}}$} & \multicolumn{4}{|c|}{ Hypotheses $2_{\mathrm{a}}$ and $2_{\mathrm{b}}$} \\
\hline & & \multicolumn{2}{|c|}{ Association } & \multicolumn{2}{|c|}{ Approval } & \multicolumn{2}{|c|}{ Attractiveness } & \multicolumn{2}{|c|}{ Similarity } \\
\hline & & RSA & USA & RSA & USA & RSA & USA & RSA & USA \\
\hline \multirow[t]{2}{*}{ Physical attractiveness } & B & $.368^{\mathrm{a}}$ & $.431^{\mathrm{a}}$ & $.290^{\mathrm{a}}$ & $.311^{\mathrm{a}}$ & & & & \\
\hline & $\eta^{2}$ & .171 & .233 & .085 & .103 & & & & \\
\hline \multirow[t]{2}{*}{ Similarity } & $\mathrm{B}$ & $.447^{\mathrm{a}}$ & $.408^{\mathrm{a}}$ & $.265^{\mathrm{a}}$ & $.340^{\mathrm{a}}$ & & & & \\
\hline & $\eta^{2}$ & .241 & .215 & .074 & .122 & & & & \\
\hline \multirow[t]{2}{*}{$\mathrm{ROC}$} & $\mathrm{B}$ & & & & & $.273^{\mathrm{b}}$ & $.193^{\mathrm{a}}$ & $.353^{\mathrm{a}}$ & $.152^{\mathrm{b}}$ \\
\hline & $\eta^{2}$ & & & & & .046 & .028 & .076 & .017 \\
\hline \multirow[t]{2}{*}{ RSE } & $\mathrm{B}$ & & & & & -.057 & -.039 & .003 & -.003 \\
\hline & $\eta^{2}$ & & & & & .003 & .002 & .000 & .000 \\
\hline \multirow[t]{2}{*}{ Gender (female) } & $\mathrm{B}$ & -.044 & -.036 & $-.187^{\mathrm{b}}$ & -.103 & $-.243^{\mathrm{a}}$ & $-.241^{\mathrm{a}}$ & -.055 & $-.210^{\mathrm{a}}$ \\
\hline & $\eta^{2}$ & .004 & .002 & .074 & .122 & .057 & .062 & .003 & .048 \\
\hline \multirow[t]{2}{*}{ OSL } & $\beta$ & & & & & -.191 & $.137^{\mathrm{b}}$ & .002 & $.188^{\mathrm{b}}$ \\
\hline & $\eta^{2}$ & & & & & .021 & .014 & .000 & .025 \\
\hline \multirow[t]{2}{*}{ Mean PQ rating } & $\beta$ & & & & & .152 & .010 & .009 & $-.153^{b}$ \\
\hline & $\eta^{2}$ & & & & & .019 & .000 & .000 & .024 \\
\hline $\mathrm{R}^{2}$ & & $.491^{\mathrm{a}}$ & $.527^{\mathrm{a}}$ & $.289^{\mathrm{a}}$ & $.350^{\mathrm{a}}$ & $.099^{\mathrm{b}}$ & $.141^{\mathrm{a}}$ & $.132^{\mathrm{a}}$ & $.138^{\mathrm{a}}$ \\
\hline
\end{tabular}

NOTE: Reported are standardized regression coefficients; $\mathrm{a}=.01, \mathrm{~b}=.05$ and $\mathrm{c}=.10$.

Table 3: Regression summaries

\begin{tabular}{|c|c|c|c|c|c|c|c|c|c|}
\hline \multirow[t]{4}{*}{ Independent Variables } & & \multicolumn{8}{|c|}{ Dependent variables } \\
\hline & & \multicolumn{4}{|c|}{ Hypotheses $3_{\mathrm{a}}$ and $3_{\mathrm{b}}$} & \multicolumn{4}{|c|}{ Hypotheses $4_{a}$ and $44_{b}$} \\
\hline & & \multicolumn{2}{|c|}{ Association } & \multicolumn{2}{|c|}{ Approval } & \multicolumn{2}{|c|}{ Association } & \multicolumn{2}{|c|}{ Approval } \\
\hline & & RSA & USA & RSA & USA & RSA & USA & RSA & USA \\
\hline \multirow[t]{2}{*}{ Physical attractiveness } & $\beta$ & & & & & $.349^{\mathrm{a}}$ & $.402^{\mathrm{a}}$ & $.268^{\mathrm{a}}$ & $.259^{\mathrm{a}}$ \\
\hline & $\eta^{2}$ & & & & & .157 & .207 & .082 & .075 \\
\hline \multirow[t]{2}{*}{ Similarity } & $\beta$ & & & & & $.413^{\mathrm{a}}$ & $.408^{\mathrm{a}}$ & $.160^{\mathrm{c}}$ & $.315^{\mathrm{a}}$ \\
\hline & $\eta^{2}$ & & & & & .202 & .212 & .030 & .108 \\
\hline \multirow[t]{2}{*}{$\mathrm{ROC}$} & $\beta$ & $.424^{\mathrm{a}}$ & $.262^{\mathrm{a}}$ & $.534^{\mathrm{a}}$ & $.326^{\mathrm{a}}$ & $.192^{\mathrm{b}}$ & $.122^{\mathrm{b}}$ & $.413^{\mathrm{a}}$ & $.227^{\mathrm{a}}$ \\
\hline & $\eta^{2}$ & .109 & .051 & .186 & .080 & .038 & .020 & .129 & .051 \\
\hline \multirow[t]{2}{*}{ RSE } & $\beta$ & -.034 & -.017 & -.009 & -.048 & -.011 & -.003 & .010 & -.034 \\
\hline & $\eta^{2}$ &. .001 & .000 & .000 & .003 & .000 & .000 & .000 & .002 \\
\hline \multirow[t]{2}{*}{ Gender (female) } & $\beta$ & $-.160^{c}$ & $-.233^{\mathrm{a}}$ & $-.246^{\mathrm{a}}$ & $-.265^{\mathrm{a}}$ & -.044 & -.050 & $-.164^{\mathrm{b}}$ & $-.134^{b}$ \\
\hline & $\eta^{2}$ & .027 & .059 & .072 & .080 & .003 & .005 & .038 & .026 \\
\hline \multirow[t]{2}{*}{ OSL } & $\beta$ & -.182 & .086 & -.202 & .075 & -.126 & -.046 & -.160 & -.015 \\
\hline & $\eta^{2}$ & .020 & .006 & .029 & .004 & .016 & .003 & .021 & .000 \\
\hline \multirow[t]{2}{*}{ Mean PQ rating } & $\beta$ & .096 & .024 & .061 & -.002 & .044 & .083 & .023 & .044 \\
\hline & $\eta^{2}$ & .008 & .001 & .004 & .000 & .003 & .013 & .001 & .003 \\
\hline $\mathrm{R}^{2}$ & & $.145^{\mathrm{a}}$ & $.154^{\mathrm{a}}$ & $.276^{\mathrm{a}}$ & $.200^{\mathrm{a}}$ & $.511^{\mathrm{a}}$ & $.545^{\mathrm{a}}$ & $.398^{\mathrm{a}}$ & $.396^{\mathrm{a}}$ \\
\hline
\end{tabular}

NOTE: Reported are standardized regression coefficients $\beta$ and effect sizes; $a=.01, b=.05$ and $c=.10$.

\section{Testing the Mediation Hypothesis}

According to Baron and Kenny (1986), if the relations between respondent value priorities and noncelebrity endorser evaluations reduce substantially in absolute size but remain statistically significant when physical attractiveness and similarity are added to the regression equations tested in $\mathrm{H}_{3 \mathrm{a}}$ and $\mathrm{H}_{3 \mathrm{~b}}$, then physical attractiveness and similarity will be identified as partial mediators of the influence of values on noncelebrity endorser evaluations. We tested $\mathrm{H}_{4 \mathrm{a}}$ and $\mathrm{H}_{4 \mathrm{~b}}$ by regressing association and approval on physical attractiveness, similarity, resultant openness to change, resultant self-enhancement, and the covariates. We then compared the results to those obtained by testing $\mathrm{H}_{3 \mathrm{a}}$ and $\mathrm{H}_{3 \mathrm{~b}}$. Although we do not hypothesise it, we note that complete mediation would occur if the significant relations of values with noncelebrity endorser evaluations became insignificant when physical attractiveness and similarity were added to the regression equations.

The results support $\mathrm{H}_{4 \mathrm{a}}$ and $\mathrm{H}_{4 \mathrm{~b}}$. The standardized regression coefficients and effect sizes for resultant openness to change decline substantially. The effect size drops from .109 to .038 (a ratio of 2.87:1) in the South African test and from .051 to .020 (a ratio of 2.55 to 1 ) in the USA test, when association is regressed on the full set of variables to test $\mathrm{H}_{4 \mathrm{a}}$. A similar result is obtained when similarity is the dependent variable in $\mathrm{H}_{4 b}$. The beta coefficient for resultant openness to change drops substantially and the effect size drops in South Africa (from .186 to .129 , a ratio of 1.44 to 1 ) and in the USA (from .080 to .051 , a ratio of 1.57 to 1 ). In all cases, the relations of resultant openness to change with noncelebrity endorser evaluations remain significant. Moreover, the overall fit of the regression equations are improved $\left(p_{F} \leq .01\right)$, when physical attractiveness and similarity are added to the equations tested in $\mathrm{H} 3 \mathrm{a}$ and $\mathrm{H} 3 \mathrm{~b}$. 


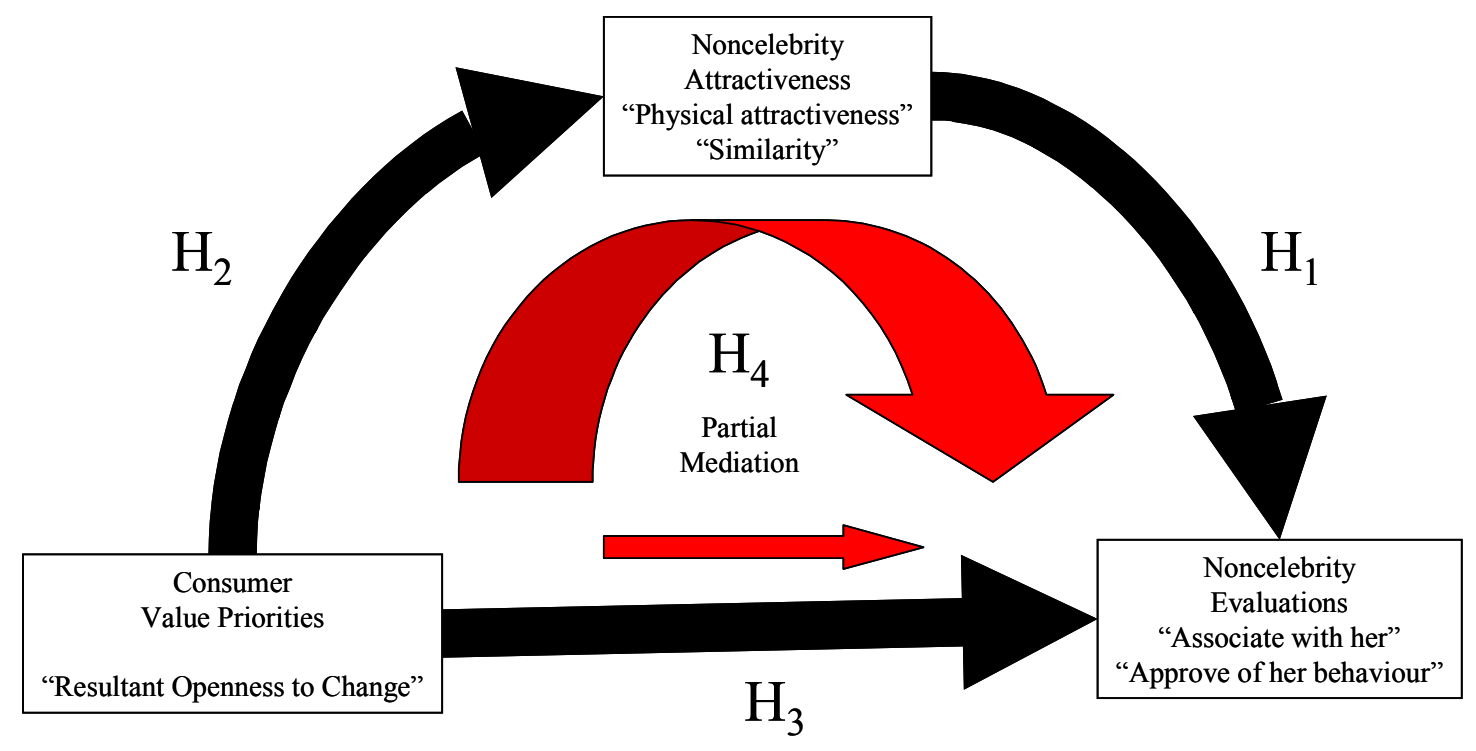

Figure 3: Testing partial mediation

Note: See Baron and Kenny (1986).

This pattern of relations, which is characterized by significant relations between $\left(\mathrm{H}_{1}\right)$ noncelebrity endorser attractiveness and noncelebrity endorser evaluations, $\left(\mathrm{H}_{2}\right)$ consumer value priorities and noncelebrity endorser attractiveness, and $\left(\mathrm{H}_{3}\right)$ consumer value priorities and noncelebrity endorser evaluations, as well as $\left(\mathrm{H}_{4}\right)$ the substantial reduction in the effect of value priorities on noncelebrity endorser evaluations in the combined regression model, suggests that similarity and attractiveness partially mediate the relationship between consumer value priorities and evaluations of noncelebrity endorsers. Thus, the results confirm hypotheses $\mathrm{H}_{4 \mathrm{a}}$ and $\mathrm{H}_{4 \mathrm{~b}}$.

Although we did not hypothesise it, we should comment on two alternative hypotheses. First, although we do not report results due to space limitations, we tested the independent variables for significant bivariate interactions. If significant interactions were detected then attractiveness would moderate (as opposed to mediate) the effect of values on noncelebrity endorser evaluations. All interactions were insignificant ( $>$.10) except the interaction of physical attractiveness and resultant self-enhancement $(p<.05)$ when association was regressed on the full set of independent variables and covariates. Because resultant selfenhancement is not related otherwise to physical attractiveness, similarity, or noncelebrity endorser evaluations, the interaction does not contradict the partial mediation hypothesis and is not germane to our results. Second, the results also allow us to test whether values mediate the effect of attractiveness on noncelebrity endorser evaluations by comparing the results of the tests for $\mathrm{H}_{4 \mathrm{a}}$ and $\mathrm{H}_{4 \mathrm{~b}}$ with the results of the tests for $\mathrm{H}_{1 \mathrm{a}}$ and $\mathrm{H}_{1 \mathrm{~b}}$. The betas and effect sizes for physical attractiveness and similarity change very little with the addition of values to the regression equation, with the exception of similarity in the South African test (the level of significance drops to $p \leq .067$ and the effect size drops from .74 to .30 , a ratio of 2.47 to 1 ). Although model fit does improve significantly when approval is the dependent variable for both the South African and USA tests
$\left(p_{F} \leq .01\right)$, the improvement is incrementally much lower than that produced by comparing $\mathrm{H}_{3}$ and $\mathrm{H}_{4}$. Thus, we do not accept these two alternative hypotheses.

\section{Discussion}

The limitation of this study to one ad, even if it is tested in two countries, is a serious limitation. Nevertheless, the results will be of interest to scholarly researchers and advertising practitioners. In this section, we briefly discuss the results of the study and suggest some implications for research.

Physical attractiveness and similarity emerged as important influences on noncelebrity endorser evaluations in the current research. As this fits into a widely replicated body of literature, it is of little surprise. Nevertheless, it is important to note that both aspects of attractiveness have rarely been tested together and emerge as roughly equivalent in their influence on noncelebrity endorser evaluations when tested together in this study. The relations of values to noncelebrity endorser evaluations also are important. These findings suggest that advertisers should carefully consider both aspects of attractiveness and the values that are activated by a noncelebrity's appearance when choosing noncelebrity endorsers, not just physical attractiveness or beauty.

The finding that the physical attractiveness and similarity of a noncelebrity endorser are related to consumer value priorities also is important. The results suggest that noncelebrity endorser attractiveness communicates information that is related to value priorities. Thus, advertisers need to study more than the copy in print ads featuring noncelebrities and consider also the information communicated by the attractiveness of the noncelebrity endorsers. Furthermore, advertisers should understand the value priorities of the target audience, as value priorities are an important influence when consumers evaluate a 
noncelebrity endorser's appearance. Attractiveness appears to be most influential when evaluating whether one would associate with a noncelebrity endorser, which in turn implies that attractiveness may be a cue that is most useful when consumers make social evaluations. Values appear to be more influential when evaluating one's approval of a noncelebrity endorser's behaviour. This suggests that values may be most useful when consumers make personal evaluations.

The most important finding of the study concerns the process of partial mediation suggested by the pattern of the statistical results. It has been argued that much work is needed to identify variables that mediate or moderate the context, content, extent, or threshold of value activation in consumer behaviour (Burgess, 1992). Kelman's theory proposes that values will be related to noncelebrity endorser evaluations directly and indirectly. The results of this exploratory study support Kelman's contentions. Identifying attractiveness as a mediator of values in the current research tells us that attractiveness may be a generative mechanism through which values influence noncelebrity endorser evaluations. Values appear to be more influential when assessing the behaviour depicted in an ad and more resistant to mediation. More tests of ads, which focus on other value types and are culled from a wide range of cultural settings, will improve our knowledge about how value priorities and perceptions of attractiveness affect consumer evaluations of noncelebrity endorsers. Source credibility was not manipulated in the current research and would provide some interesting additional future insights. Manipulating source and message discrepancy also may provide insights about values in the context of the dual process theories of persuasion.

We note that the OSL covariate did not emerge as a consistent influence on noncelebrity endorser evaluations. This may be due to the nature of the test (a brief exposure to the ad). High OSL consumers have been characterized as engaging in multiple activities while consuming media (with important implications for sustained attention) and having a strong capacity to focus short-term attention on a single or multiple stimuli or tasks such as finding simple figures embedded in more complex and distracting figures, and as having a tendency for broad cognitive generalizations and more complex cognitive categorization (Zuckerman, 1994). These processing style differences may decrease the effect of OSL during relatively brief ad exposures such as in the current research. The distinction between values and traits may be informative. Values are deeply-held goals that are the cognitive transformation of needs. Means-end chain research has shown that consumers relate values to less central goals, attitudes and perceptions that are activated by advertising stimuli during ad evaluations. OSL is a personality trait that is thought to influence behaviour directly and not by mediating the influence of other variables (Joachimsthaler \& Lastovicka, 1984). Thus, it may not always be referenced during brief ad exposures. Values may mediate the influence of OSL and involvement may mediate both. However, the current study is not sufficient to make an informed judgement on the influence of OSL.
We appreciate the limitations arising from a cross-sectional study based on one ad. Nevertheless, we close by calling attention to the importance of these findings and the need for additional research. Such research will have important implications for marketing science and advertising.

\section{References}

Aaker, D.A. \& Stayman, D.M. 1989. What mediates the emotional response to advertising? The case of warmth. In Cafferata, P. \& Tybout, A. (Eds.). Cognitive and affective responses to advertising. Mass.: Lexington, pp. 287-304.

Agrawal, J. \& Kamakura, W.A. 1995. 'The economic worth of celebrity endorsers: An event study analysis,' Journal of Marketing, 59: 56-62.

Aitken, P.P. 1989a. 'Alcohol advertising in developing countries,' British Journal of Addiction, 84:1443-1445.

Aiken, P. P. 1989b. 'Television alcohol commercials and underage drinking,' International Journal of Advertising, 8:133-50.

Aitken, P. P., Eadie, D. R., Leathar, D. S., McNeill, R. E. J. \& Scott, A.C. 1988. 'Television advertisements for alcoholic drinks do reinforce under age drinking', British Journal of Addiction, 83: 1399-1419.

Allen, M.W. \& Ng, S.H. 1998. 'The direct and indirect influences of human values on product ownership,' Journal of Economic Psychology, 20 (1): 5-39.

Bagozzi, R.P. 2000. 'Discursive psychology: An alternative conceptual foundation to means-end chain theory', Psychology and Marketing, 17 (7):535-86.

Bagozzi, R.P., Baumgartner, H. \& Pieters, R. 1998. 'Goaldirected emotions', Cognition and Emotion, 12 (1):1-26.

Bagozzi, R. P. \& Dabholkar, P.A. 1994. 'Consumer recycling goals and their effect on decisions to recycle: A means-end chain analysis', Psychology \& Marketing, 11 (4):313-40.

Baron, R. M. \& Kenny, D.A. 1986. 'The moderator-mediator variable distinction in social psychological research: Conceptual, strategic, and statistical considerations', Journal of Personality and Social Psychology, 51(6):1173-82.

Baumgartner, H., Sujan, M. \& Bettman, J.R. 1992. 'Autobiographical memories, affect, and information processing', Journal of Consumer Psychology, 1 (1):53-82.

Berscheid, E. \& Reis. H.T. 1998. Attraction and close relationships. In Gilbert, D.T., Fiske, S.T. \& Lindzey, G. (Eds.). The handbook of social psychology, Vol. 2. New York: McGraw Hill.

Biddle, B.J., Bank, B.J. \& Marlin, M.M. 1980. 'Social determinants of adolescent drinking: What they think, what they do and what I think and do', Journal of Studies on Alcohol, 41(3): 215-41. 
Biernat, M., Vescio, T.K., Theno, S.A. \& Crandall, C.S. 1996. Values and prejudice: Toward understanding the impact of American values on outgroup attitudes. In Seligman, C., Olson, J.M. \& Zanna, M.P. (Eds.). The psychology of values: The Ontario Symposium, Vol. 8. Hillsdale, New Jersey: Lawrence Erlbaum, pp. 153-190.

Breed, W. \& DeFoe, J.R. 1979. 'Themes in magazine alcohol advertisements', Journal of Drug Issues, 9(4):511-22.

Brewer, M.B. \& Brown, R.J. 1998. Intergroup relations. In Gilbert, D.T., Fiske, S.T. \& Lindzey, G. (Eds.). The handbook of social psychology, Vol. 2. Boston: McGraw-Hill, pp. 554-594.

Burgess, S.M. 1992. Personal values and consumer research: An historical perspective. In Research in Marketing, 11: 35-79.

Burgess, S.M. \& Blackwell, R.D. 1994. 'Personal values and South African financial services brand preference', South African Journal of Business Management, 25 (1): 22-29.

Burgess, S.M. \& Steenkamp, J-B.E.M. 1999. Value priorities and consumer behavior in a transitional economy: The case of South Africa. In Rajeev, B. (Ed.). Marketing issues in transitional economies. Norwell, Mass.: Kluwer Academic Press, pp. 85-105.

Byrne, D., London, O. \& Reeves, K. 1968. 'The effects of physical attractiveness, sex, and attitude similarity on interpersonal attraction', Journal of Personality, 36:259-71.

Camilleri, C. \& Malewska-Peyre, H. 1997. Socialization and identity strategies. In Berry, J.W., Dassen, P.R. \& Saraswati, T.S. (Eds.). Handbook of cross-cultural psychology, Vol. 2. 2nd Edition. Boston: Allyn and Bacon, pp.41-68.

Chaiken, S. 1980. 'Heuristic versus systematic information processing and the use of source and message cues in persuasion', Journal of Personality and Social Psychology, 39: 752-66.

Chaiken, S. 1979. 'Communicator physical attractiveness and persuasion', Journal of Personality and Social Psychology, 37: 1387-97.

Cunningham, M. R., Roberts, A.R., Barbee, A.P., Druen, P.B. \& Wu, C-H. 1995. ' 'Their ideas of beauty are, on the whole, the same as ours': Consistency and variability in the cross-cultural perception of female physical attractiveness', Journal of Personality and Social Psychology, 68 (2):261-79.

DePaulo, B.M. 1992. 'Nonverbal behavior and selfpresentation', Psychological Bulletin, 111:203-43.

Eagly, A.H., Ashmore, R.D., Makhijani, M.G. \& Longo, L.C. 1991. 'What is beautiful is good, but ...: A meta-analytic review of research on the physical attractiveness stereotype,' Psychological Bulletin, 110 (1):109-28.

Eagly, A.H. \& Chaiken, S. 1993. The psychology of attitudes. Fort Worth, Texas: Harcourt Brace.

Engel, J.F., Kollat, D.T. \& Blackwell, R.D. 1968. Consumer behavior. New York: Dryden.

Feather, N.T. 1995. 'Values, valences, and choice: The influence of values on the perceived attractiveness and choice of alternatives', Journal of Personality and Social Psychology, 68 (6):1135-51.

Feingold, A. 1992. 'Good-looking people are not what we think', Psychological Bulletin, 111(2):304-41.

Finn, T.A. \& Strickland, D.E. 1982. 'A content analysis of beverage alcohol advertising: II. Television advertising', Journal of Studies on Alcohol, 42(9):964-89.

Frankl, V.E. 1959. Man's search for meaning. Boston: Beacon.

Grunert-Beckmann, S. C. \& Askegaard, S. 1997. 'Seeing with the mind's eye': On the use of pictorial stimuli in values and lifestyle research. In Kahle, L.R. \& Chigouris, L. (Eds.). Values, lifestyles, and psychographics. Mahwah, New Jersey: Lawrence Erlbaum Associates, pp. 161-182.

Guttman, L. 1968. 'A general nonmetric technique for finding the smallest coordinate space for a configuration of points', Psychometrika, 33 (4):469-506.

Hart, B. \& Diehl, V.A. 1994. 'Position reversal: Isolating the key factor in assimilation and contrast', Journal of Psychology, 128:71-87.

Higgins, E.T. 1996. 'The 'Self Digest': Self-knowledge serving self-regulatory functions', Journal of Personality and Social Psychology, 71(6):1062-83.

Hirschman, E.C. 1984. 'Experience seeking: A subjectivist perspective of consumption', Journal of Business Research, 12: 115-36.

Jackson, L.A., Hunter, J.E. \& Hodge, C.N. 1995. 'Physical attractiveness and intellectual competence: A meta-analytic review, 'Social Psychology Quarterly, 58(2):108-22.

Jackson, L.A., Sullivan, R.H. \& Hodge, C.N. 1996. 'Achieving positive social identity: Social mobility, social creativity and permeability of group boundaries', Journal of Personality and Social Psychology, 70(2):241-54.

Jetten, J. Spears, R. \& Manstead, A.R.S. 1996. 'Intergroup norms and intergroup discrimination: Distinctive selfcategorization and social identity effects', Journal of Personality and Social Pschology, 71(6):1222-233.

Joachimsthaler, E.A. \& Lastovicka, J.L. 1984. 'Optimal stimulation level - Exploratory behavior models', Journal of Consumer Research, 11(3):830-35.

Johnson, B.T. \& Eagly, A.H. 1990. 'Involvement and persuasion: Types, traditions, and the evidence', Psychological Bulletin, 107(3):375-84.

Kahle, L.R. \& Homer, P.M. 1985. 'Physical attractiveness of the celebrity endorser: A social adaptation perspective', Journal of Consumer Research, 11: 954-61. 
Kamins, M.A. 1990. 'An Investigation into the 'Match-Up' hypothesis in celebrity advertising: When beauty may be only skin deep', Journal of Advertising, 19(1):4-13.

Kelman, H.C. 1961. 'Processes of opinion change', Public Opinion Quarterly, 25(1):57-78.

McAlister, L. \& Pessemier, E.A. 1982. 'Variety seeking behavior: An interdisciplinary review', Journal of Consumer Research, 9: 311-22.

McCarty, J.A. \& Shrum, L.J. 1993. 'The role of personal values and demographics in predicting television viewing behavior: Implications for theory and application', Journal of Advertising, 22(4):77-101.

Olson, J.C. 1995. 'Special issue: Means-end chains', International Journal of Research in Marketing, 12 (3).

Pechmann, C. and Shih, C-F. 1999. 'Smoking scenes in movies and antismoking advertisements before movies: Effects on youth', Journal of Marketing, 63:1-13.

Petty, R.E. \& Cacioppo, J.T. 1986. Communication and persuasion: Central and peripheral routes to attitude change. New York: Springer-Verlag.

Pieters, R., Baumgartner, H. \& Allen, D. 1995. 'A means-end chain approach to consumer goal structures', International Journal of Research in Marketing, 12(3):227-44.

Postman, L. \& Scheider, B. 1951. 'Personal values, visual recognition, and recall', Psychological Review, 58:271-84.

Raju, P.S. 1980. 'Optimum stimulation level: Its relationship to personality, demographics, and exploratory behavior', Journal of Consumer Research, 7 :272-82.

Reynolds, T.J., Gengler, C.E. \& Howard, D.J. 1995. 'Meansend analysis of brand persuasion through advertising', International Journal of Research in Marketing, 12(3):257-66.

Rokeach, M. 1973. The nature of human values. New York: Free Press.

Schooler, C., Basil, M.D. \& Altman, D.G. 1996. 'Alcohol and cigarette advertising on billboards: Targeting with social cues', Health Communication, 8(2):109-29.

Schwartz, S. 1992. 'Universals in the content and structure of values: Theoretical advances and empirical tests in 20 countries', Advances in Experimental Social Psychology, 25:149.

Schwartz, S. 1994. 'Are there universal aspects in the content and structure of human values?', Journal of Social Issues, 50(4):19-45.

Schwartz, S., Lehmann, A., Melech, G., Burgess, S.M. \& Harris, M. 2001. 'Validation of a theory of basic human values with a new instrument in new populations', Journal of CrossCultural Psychology, in press.

Schwartz, S., Lehmann, A. \& Roccas, S. 1999. Multimethod probes of basic human values. In Adamopoulos, J. \& Kashima, Y. (Eds.). Social psychology and cultural context. Newbury Park, California: Sage, pp. 107-124.

Steenkamp, J-B.E.M., Ter Hofstede, F. \& Wedel, M. 1999. 'A cross-national investigation into the individual and cultural antecedents of consumer innovativeness', Journal of Marketing Research, 36: 1-17.

Steenkamp, J-B.E.M. \& Baumgartner, H. 1995. 'Development and cross-cultural validation of a short form CSI as a measure of optimum stimulation level', International Journal of Research in Marketing, 12(2):97-104.

Steenkamp, J-B.E.M. \& Baumgartner, H. 1992. 'The role of optimum stimulation level in exploratory consumer behavior', Journal of Consumer Research, 19:434-48.

Strickland, D.E., Finn, T.A. \& Lambert, M.D. 1982. 'A content analysis of beverage alcohol advertising I: Magazine advertising', Journal of Studies on Alcohol, 43(7):655-82.

Tanke, E.D. 1982. 'Dimensions of the physical attractiveness stereotype: A factor/analytic study', Journal of Psychology, 110:63-74.

Ter Hofstede, F., Steenkamp, J-B.E.M. \& Wedel, M. 1999. 'International market segmentation based on consumer-product relations', Journal of Marketing Research, 36:1-17.

Till, B.D. \& Shimp, T.A. 1998. 'Endorsers in advertising: The case of negative celebrity information', Journal of Advertising, 27(1):67-83.

Tripp, C., Jensen, T.D. \& Carlson, L. 1994. 'The effects of multiple product endorsements by celebrities on consumers' attitudes and intentions', Journal of Consumer Research, 20:535-47.

Turner, J.C. 1984. Social identification and psychological group formation. In Tajfel, H. (Ed.) The social dimension, Vol. 2. Cambridge, England: Cambridge University Press, pp. 518-540.

Van Raaij, W.F. 1989. 'How consumers react to advertising', International Journal of Advertising, 8:261-73.

Wilson, E.J. \& Sherrell, D.L. 1993. 'Source effects in communication and persuasion research: A meta-analysis of effect size', Journal of the Academy of Marketing Science, 21(2):101-12.

Woodside, A.G. \& Davenport, J.W. (Jr.) 1997. 'The effect of salesman similarity and expertise on consumer purchasing behaviour', Journal of Marketing Research, 6:198-202.

Zavalloni, M. 1975. 'Social identity and the recoding of reality: Its relevance for cross-cultural psychology', International Journal of Psychology, 10 (3):197-217.

Zuckerman, M. 1994. Behavioral expressions and biosocial bases of sensation seeking. Cambridge, England: Cambridge University Press. 


\section{Acknowledgments}

The authors thank Shalom Schwartz of the Hebrew University of Jerusalem and Jan-Benedict Steenkamp of Tilburg University in The Netherlands for permission to use their values and OSL scales, respectively, and helpful comments. We also thank Michael Bond of the Chinese University of Hong Kong for helpful comments on an earlier version of this paper and Theo Dagiakidis and Sam Min for assistance with data collection. 